\title{
Ventricular assistant in restrictive cardiomyopathy: Making the right connection
}

\author{
Robert D. B. Jaquiss, MD
}

\author{
From the Department of Cardiothoracic Surgery, Duke University School of Medicine, Durham, NC. \\ Disclosures: Author has nothing to disclose with regard to commercial support. \\ Received for publication Aug 24, 2015; accepted for publication Aug 24, 2015; available ahead of print Sept 19 , \\ 2015. \\ Address for reprints: Robert D. B. Jaquiss, MD, Department of Cardiothoracic Surgery, Duke University School \\ of Medicine, DUMC 3474, Durham, NC 27710 (E-mail: robert.jaquiss@ duke.edu). \\ J Thorac Cardiovasc Surg 2016;151:e15-6 \\ $0022-5223 / \$ 36.00$ \\ Copyright (C) 2016 by The American Association for Thoracic Surgery \\ http://dx.doi.org/10.1016/j.jtcvs.2015.08.085
}

In the past few years, the use of mechanical circulatory support in the form of ventricular assist devices (VADs) as a bridge to transplant for patients with severe heart failure has become routine for patients of all ages and (almost) all diagnoses. In the majority of patients, the dysfunctional systemic ventricle is pathologically dilated, and the connection from this capacious ventricle to the support pump is easily accomplished by ventricular apical cannulation. However, in the minority of patients whose heart failure is caused by restrictive or hypertrophic cardiomyopathy, the systemic ventricular cavity may be very small. In such cases, the standard route of inflow cannulation of the left ventricular apex carries a significant risk of obstruction. The obstruction may be caused by free wall or septal muscle, papillary muscles, or even mitral valve leaflet and chordal tissue. Because of these concerns, there may be a reluctance to offer VAD therapy for patients with heart failure with restrictive physiology (restrictive cardiomyopathy or hypertrophic cardiomyopathy), and the pivotal trials with currently approved adult VADs did not include such patients. $^{1,2}$

In the present report, Tunuguntla and colleagues ${ }^{3}$ describe a patient with restrictive cardiomyopathy in whom an initially satisfactory apical cannulation strategy was modified in response to the rapid development of inflow cannula obstruction. After removing the original cannula and enlarging the apical ventriculotomy, the authors excised the native mitral valve and all of its subvalvular apparatus, including the papillary muscles. They then implanted a small bioprosthesis, closed the ventriculotomy, and replaced the apical cannula. This effectively relieved the inflow obstruction, and the patient was supported for several weeks, albeit with the subsequent implantation of an rightsided VAD, until he underwent successful transplantation. This approach was logical, direct, and successful, and should be borne in mind by surgeons caring for similar patients in the future. Although not stated by the authors, presumably in the future they might recommend proceeding directly to this approach without first trying to avoid it by apical cannulation alone.

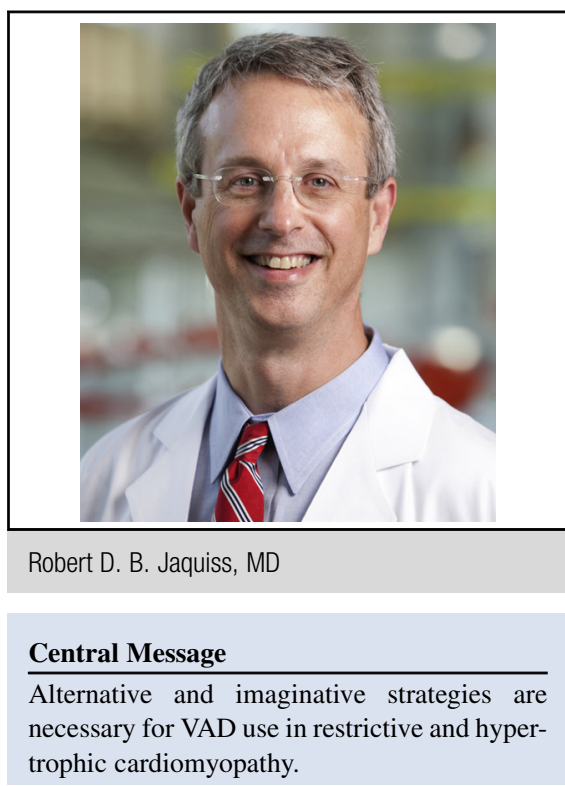

See Article page e11.

Alternative initial approaches should be considered. As Tunuguntla and colleagues ${ }^{3}$ describe in their report, left atrial cannulas are available for the particular VAD they used (Berlin Heart EXCOR, The Woodlands, Tex). Indeed, the initial clinical use of the Berlin Heart device was exclusively with the left atrial cannula, although apical cannulation was eventually thought to be superior. ${ }^{4}$ The company continues to manufacture the left atrial cannula, and, as the authors of the present report acknowledge, results with atrial cannulation have been acceptable in children with restrictive cardiomyopathy. I am aware of at least 1 instance in which apical cannulation was converted to atrial cannulation with successful long-term support in a child (R. R. Davies, MD, personal communication, August 2015).

If atrial cannulation is not feasible, as with continuousflow VADs that require apical attachment, a less radical approach, sparing the mitral valve and its papillary muscles, has been reported to be successful. ${ }^{5,6}$ In 1 case report, a particularly aggressive left ventricular myectomy actually resulted in the appearance of a flail segment of the mitral valve. ${ }^{7}$ Despite this potential for significant mitral regurgitation, the patient was well supported with a continuousflow VAD for 4 months before undergoing successful transplantation. This experience certainly raises the unanswered question of whether a mitral valve is necessary in the setting of continuous-flow support. 
However, in the presence of a pulsatile VAD, the question is probably moot, because approximately half of the pump "cardiac" cycle is spent in systole, during which time the native ventricle may contract and elevate the left atrial pressure in the presence of an absent or incompetent mitral valve. If a mitral valvectomy is added to a myectomy, some sort of prosthetic valve must be inserted. Tunuguntla and colleagues $^{3}$ elected to use a bioprosthesis, which has substantially more intracavitary mass than a typical bileaflet mechanical prosthesis. From the perspective of maximization of ventricular cavity volume, it might be suggested that a mechanical prosthesis would be preferred, particularly given the salutary experience reported in adult patients with a VAD and preexisting mechanical prostheses. ${ }^{8}$ Because Berlin Heart recipients are typically intensely anticoagulated, there would presumably not be any need for modification of the anticoagulation regimen. On the other hand, implantation of a bioprosthesis would allow for temporary reduction in anticoagulation intensity, which sometimes may be necessary in the event of perioperative bleeding or other hemorrhagic complication. In any case, the success of the approach taken by the authors speaks for itself. This case represents an aggressive and imaginative solution to a vexing problem, with potential application to both adult and pediatric VAD recipients.

\section{References}

1. Miller LW, Pagani FD, Russell SD, John R, Boyle AJ, Aaronson KD, et al. HeartMate II Clinical Investigators. Use of a continuous-flow device in patients awaiting heart transplantation. $N$ Engl J Med. 2007;357:885-96.

2. Slaughter MS, Rogers JG, Milano CA, Russell SD, Conte JV, Feldman D, et al. HeartMate II Investigators. Advanced heart failure treated with continuous-flow left ventricular assist device. N Engl J Med. 2009;361:2241-51.

3. Tunuguntla H, Denfield SW, McKenzie ED, Adachi I. Mitral valve replacement for inflow obstruction of left ventricular assist device in a child with restrictive cardiomyopathy. J Thorac Cardiovasc Surg. 2016;151:e11-3.

4. Hetzer R, Potapov EV, Stiller B, Weng Y, Hübler M, Lemmer J, et al. Improvement in survival after mechanical circulatory support with pneumatic pulsatile ventricular assist devices in pediatric patients. Ann Thorac Surg. 2006;82:917-25.

5. Topilsky Y, Pereira NL, Shah DK, Boilson B, Schirger JA, Kushwaha SS, et al. Left ventricular assist device therapy in patients with restrictive and hypertrophic cardiomyopathy. Circ Heart Fail. 2011;4:266-75.

6. Singh M, Parameshwar J, Lewis C, Tsui SS. Biventricular assist device use in nondilated hypertrophic cardiomyopathy. Eur J Cardiothorac Surg. 2015;47:929-30.

7. Wynne E, Bergin JD, Ailawadi G, Kern JA, Kennedy JL. Use of a left ventricular assist device in hypertrophic cardiomyopathy. J Card Surg. 2011;26:663-5.

8. Goda A, Takayama H, Koeckert M, Pak SW, Sutton EM, Cohen S, et al. Use of ventricular assist devices in patients with mitral valve prostheses. J Card Surg. 2011;26:334-7. 